\title{
THE SURVEY OF THE MONUMENTAL FOUNTAIN IN THE TOWN OF DALMINE: A PRELIMINARY WORK FOR THE CONSERVATION PROJECT
}

\author{
A. Cardaci ${ }^{1}$, P. Azzola ${ }^{1}$, A. Versaci ${ }^{2}$ \\ ${ }^{1}$ Department of Engineering and Applied Sciences, University of Bergamo, Italy \\ alessio.cardaci@unibg.it - pietro.azzola@unibg.it \\ ${ }^{2}$ Faculty of Engineering and Architecture, University of Enna ‘Kore', Enna, Italy - antonella.versaci@unikore.it
}

\section{Commission I, WG 4}

KEY WORDS: Laser scanning, 3D modelling, Diagnostics, Conservation, Bergamo.

\begin{abstract}
:
The Monumental Fountain of Dalmine was built to celebrate the $20^{\text {th }}$ anniversary of Benito Mussolini's historical address held on March 20, 1919, to which the square was dedicated. In the basin stood a large marble block on which some sentences of the Duce's speech were carved. The work was partially destroyed at the end of the World War II and the block was removed. Today, what remains of the Dalmine Fountain constitutes the privileged meeting place of the city. However, it has great sealing problems as well as high management and maintenance costs, which prevent its normal functioning. Consequently, it is kept empty for many months of the year and filled with water only in the summer. This essay intends to propose a study based on the analysis of historical sources and 3D survey and modelling techniques aimed to understand the historical and urban value of the monument, to support its conservation and to enhance its role as a central meeting point for the town.
\end{abstract}

\section{INTRODUCTION}

The city of Dalmine, located in the surroundings of Bergamo in northern Italy, still shows clearly visible the traces of the utopian design of the company town that arose in the first half of the last century: a village made up of houses for workers, schools, guest houses, canteens, small shops, company outlets and even farms. The small town was born amid the social tension that was then growing in Italy, which had dramatically changed by the World War I, despite Italy's victorious emergence from it. It embodied the will to create a new symbolic place that would represent an ideal society in which the company set as its ultimate goal the well-being and serenity of the workers.

Dalmine's origins date back to the beginning of the $20^{\text {th }}$ century, when the company Deutsch-Österreichische Mannesmannröhren-Werke of Düsseldorf, after having purchased vast lands in the Bergamo plain along the railway line to Milan, began constructing a plant for the manufacture of tubular steel profiles extruded without welding (the patented Mannesmann method). The small industry expanded during the World War I thanks to the need for arms manufacture. However, after the conflict ended, the company ceased production and was not able to convert to another type of manufacturing. The consequent economic and social crisis was the cause, in March 1919, of the occupation of the plant by the workers who, having dismissed the company managers, reorganised the industry to one of self-management without ever interrupting production, even during their strike.

The Italian flag was raised on the highest pole of the plant as a sign of devotion to work and homeland, an episode that aroused great consensus and was much publicised by Il Popolo d'Italia, the newspaper founded by Benito Mussolini in 1914, after his split from the Italian Socialist Party. This form of protest, new to the European panorama, also saw the participation, on 20 March 1919 , of the future Duce, who exalted the revolt through which the workers, although devoted to their jobs, worked for the sake of the nation (Lussana, 2003).

The importance achieved at the time by the factory is evidenced by the dual role held by its administrative director Ciro Prearo who, in the spring of 1926, was appointed podestà of the three municipalities of Sabbio Bergamasco, Sforzatica and Mariano al Brembo. In January 1927, he deliberated the abolition of those ancient entities and the establishment of the new and unique municipality of Dalmine (Royal Decree of 7 July 1927). A new urban design was entrusted by Mario Garbagni, at that time president of the factory, to his friend Giovanni Greppi. The Milanese architect was asked to design an ideal village, a 'self-sufficient microcosm' designed to meet the needs of employees and their families, with both residences for them and public structures designated for social, cultural and welfare purposes.

The new city was built during a short but controversial period of time due to rapid political and social changes. Its centre was established only at the end of the 1930s on a regular layout characterised by two large squares. The first square - Piazza dell'Impero - was conceived as a large circular space with a flagpole in the centre, the highest in Europe, on which would wave the flag of the nation. Around it, the administrative buildings of the city the Casa Littoria, the Town Hall and the Dopolavoro - were built. The second square, larger in size - Piazza 20 Marzo 1919, in memory of Mussolini's speech - was located next to the churchyard and in front of both the entrance and the administrative buildings of the factory (Fig. 1). A large basin still stands in the middle of this square, which is framed on the northern and western sides by residential buildings and shops (Cardaci \& Versaci, 2019). A central fountain had been conceived as a commemorative monument created by the master Castiglioni. In the basin, stood a large marble block on which sentences from the Duce's speech were carved.

The work was partially destroyed at the end of the World War II, and this imponent structure was removed. Today, what remains of the Dalmine fountain constitutes the privileged meeting place of the city. However, it suffers from major sealing problems as well as high management and maintenance costs, which prevent its normal functioning. Consequently, it is kept empty for many months of the year and filled with water only in the summer.

This essay intends to show the importance of preliminary studies for the conservation of this asset. It is based on the analyses of 
historical sources and 3D survey and modelling techniques aimed at understanding the historical and urban value of the monument for the purpose of supporting its safeguarding and enhancement.

\section{THE MONUMENTAL FOUNTAIN OF DALMINE}

The Dalmine fountain is the emblem of an articulated urban project. It is part of a simple yet refined layout, covering an entire city block overlooking the manufacturing plant's office buildings. Cleared of earlier construction in 1938, the area underwent a radical transformation after 16 January 1939 (Lussana et al., 2019). Enclosed by the churchyard and bounded by the ancient town hall and the 'arcades', with their Mannesmann tube colonnade shading shops and clubs, for a long time it played the role of the city's 'best parlour'.

The monument is the work of the architect Giovanni Greppi and the sculptor Giannino Castiglioni. It was built to celebrate the $20^{\text {th }}$ anniversary of Benito Mussolini's historic address delivered on 20 March 1919, to which the square was dedicated. The plant's management decided to engrave the words spoken by the Duce (Ronchi, 1939) on the large vertical volume of marble placed in the centre of the basin. The fountain was completed in a very short period of time, only 60 days, and its inauguration took place on 29 March 1939 (Fig. 2).

Greppi's design included a regular composition of watersheds, green spaces and paved areas: a space conceived as a place of pleasure, where citizens could find refreshment by listening to the sound of water and enjoying the scent of flowers. A simple geometry set along the longitudinal axis of the monolith and regulated by precise modular ratios, which the graphic analysis conducted starting from the three-dimensional model obtained from the survey, has highlighted.

All of its components respond to a rigorous system of proportions that can be read both in plan and in elevation. The square is slightly irregular and contains three concentric rectangles. The interior consists of the basin, surrounded by the water collection channel, which is fed by four weirs that create as many 'waterfalls'. From the ordering element of the entire spatial system rises the large monolith, located in an eccentric position, but on the axis of the basin, with a cylindrical pedestal in front (perhaps the base for a sculpture that was never placed). The central rectangle is a paved filter area between the pool and the green space; to the east, it ends with a large semicircle: a raised structure with a single high step, similar to a small stage. Finally, the third and outermost rectangle consists of the green system. Open at the east, toward the church, it originally contained three flowerbeds with lawns and small flowering bushes. Twenty-two benches of soft shapes made from blocks of Ceppo di Gré surround the area. Protected by the shade of large pines, they are coupled to face both the fountain and the outside, and, on the long sides, they once framed two flowerbeds.

Original design of the square is unfortunately missing. However, images of the maquette created to present the work to the factory's board of directors are available, as well as two documentaries produced by the film company Industria Cortometraggi Milano (INCOM), today kept in the archive of the Istituto Luce (Gandin, 1941). The original idea of an independent urban system, bordered by a dense series of trees and delimited by the four streets, is evident. The monolith, narrow and tall, fulfilled the function of shielding and conditioning the vision, directing the eye toward particular points of view. The system was designed to communicate with the arcaded building on one side and the plant management on the other.

As already mentioned, with the fall of fascism, after the World War II, the monument was mutilated with the demolition of the massive marble wall. The composition, based on the contrast

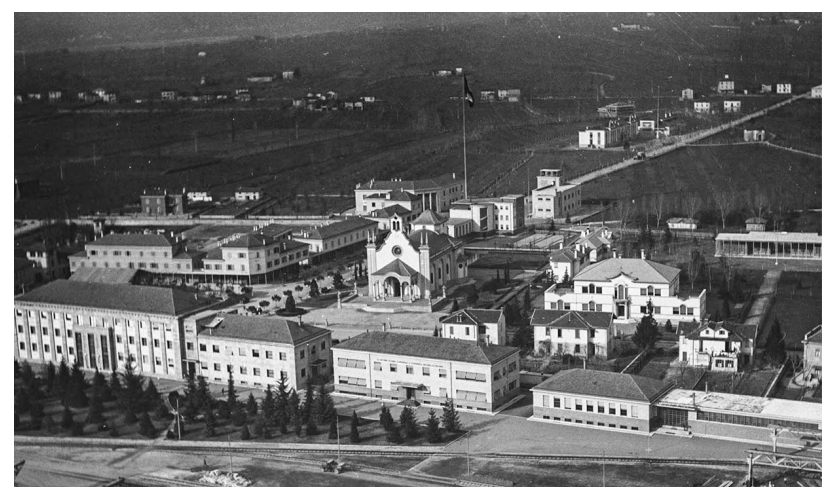

Figure 1. The center of the town of Dalmine in the 1930s

between the horizontal of the vessel and the verticality of the monolith, was seriously compromised. The artifact ceased being a monument to the city and became a mere reservoir. As such, the fountain has lost its singularity and has simply turned into a calm presence. Persistent attempts to remedy the situation since the early 1950s included the arrangement of a flowerbed in place of the monolith, followed in the 1970s with a series of tall vertical pipes with sprays of water. This solution was quickly abandoned due to the constant flooding of the surrounding area caused by wind.

The pedestrianisation and pavement uniformity that accompanied the unification of the former block with the two northwest streets, as well as the replacement of flowerbeds with a paved walking surface, make the original urban design difficult to read today (Fig. 3).

Over the years, several proposals to embellish and modernise the monument have been suggested. Among the latest initiatives is that of the artist Luigi Oldani, who imagined creating a golden bronze casting titled 'Imago Vitae', a statue emerging from the water 'to celebrate the rebirth to the life of a witness of death', referring to the victims of the bombings that hit the factory on 6 July 1944, to which the square is now dedicated.

The fountain, neglected over the years, is no longer used today due to significant losses of water (30-40 cubic metres per day). Being no longer waterproof, the fountain's water is dispersed through cracks in the tank underground to the aquifer. This phenomenon forced the municipality to forego reactivating the fountain last year, also due to the danger to the environment of dispersed acid substances (e.g. chlorine and antifouling biocides).

Currently, maintenance activities have been envisaged and the area has been bounded by wooden enclosures. However, any conservation project has to be designed and submitted to the local Superintendence for the necessary approval. Meanwhile, the citizens of Dalmine are deprived of not only the enjoyment of the fountain but also of the vision and usage of the urban square.

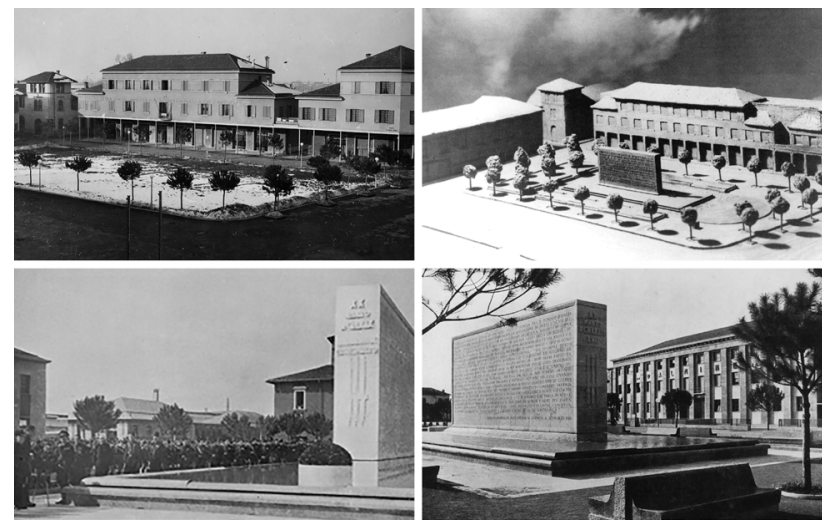

Figure 2. The fountain of Dalmine: from the origin until the World War II 

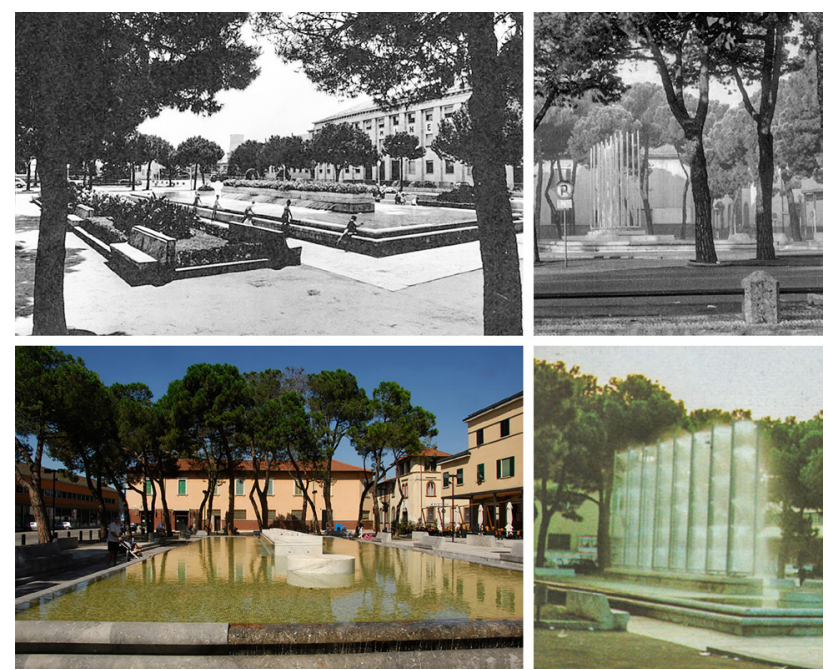

Figure 3.The fountain of Dalmine: from the early 1950 s to the present

\section{THE INTEGRATED SURVEY}

The survey, seen as an instrument aimed at the metric and material understanding of a physical asset, is now taking advantage - much more than in the past - of integrated measurement techniques. New 3D models represent the visualisation of an extensive database on the monument, studied by establishing a direct contact with it and measured by different instruments (Fig. 4).

The new working environments provide the possibility of importing and digitally merging the best data obtained by the different sensors. On the one hand, topography allows us to discern the positions of only a few targets, but with very high precision. On the other hand, laser scanners deliver dense and accurate point clouds. Finally, photogrammetry gives us realistic and accurate colorimetric data.

The traditional differentiation between the three methodologies is now obsolete, just like the (very Italian) differentiation between the 'direct' survey, the type of survey made by architects, and the 'instrumental' survey, the type of survey made by engineers. An idea related to the past and conditioned by the limited technological opportunities of the time before the advent of the electronic age (Paris, 2011).

At the same time, the digital revolution has brought significant change, being an event that took place over the course of a few years, between the end of the old and the beginning of the new millennium. This transformation has radically changed the way an inquiry is conducted, both in the process and in the final products, through the introduction of virtual models. The study of cultural heritage has particularly benefited from this upheaval. That is, a monument needs to be rendered in its free form and with a great wealth of detail. In addition, it must be characterised by information resulting from matter, construction, stratigraphic and decay analysis.

Traditional (optical and analogue) photogrammetry techniques were not suitable for obtaining 3D models of cultural heritage. This was due both to the difficulty of acquiring and processing a very large number of images and to the problems of measuring benchmarks and compensating for errors. The processes demanded a greater commitment on the part of the surveyor and the stereo-plotter operator, which called for a tremendous amount of manual work. Processing systems were not automated, notably due to a lack of current measurement and processing tools (software and hardware). It was easier to redraw an elevation or a vertical cross-section, or even a plan view starting from a still life sketch (the so-called eidotype), than to redesign them, based on a few often-inaccurate measurements.

The introduction of electronic telescopes and distance meters in the early 1970s and the invention of the total station in the 1980s made topographic measurements simpler and more reliable, thereby improving productivity (Dequal, 1994). This also enabled the rapid production of the first photoplans: corrected and resized images based on coordinate points, i.e. the antecedent of the current orthographic projections, although they still were conical images affected by perspective distortion. Nevertheless, it was only with the advent of digital frames in the 1990s, when photosensitive film was replaced by an electronic sensor (Carpiceci, 2012), that photogrammetry became widely used. Progressevely, this technique will become accessible to all, so it will not be limited to a few operators experienced in the use of complex analogue stereoplotters. Almost simultaneously, laser sensors (on the market since the first decade of the new century) began to make familiar discontinuous models consisting of sets of points in space, or the so-called point cloud:

a true three-dimensional image of the reality [...]. Photogrammetry makes it possible to reconstruct the position, orientation, shape and size of objects from images. These images may originate from photochemical images (con-
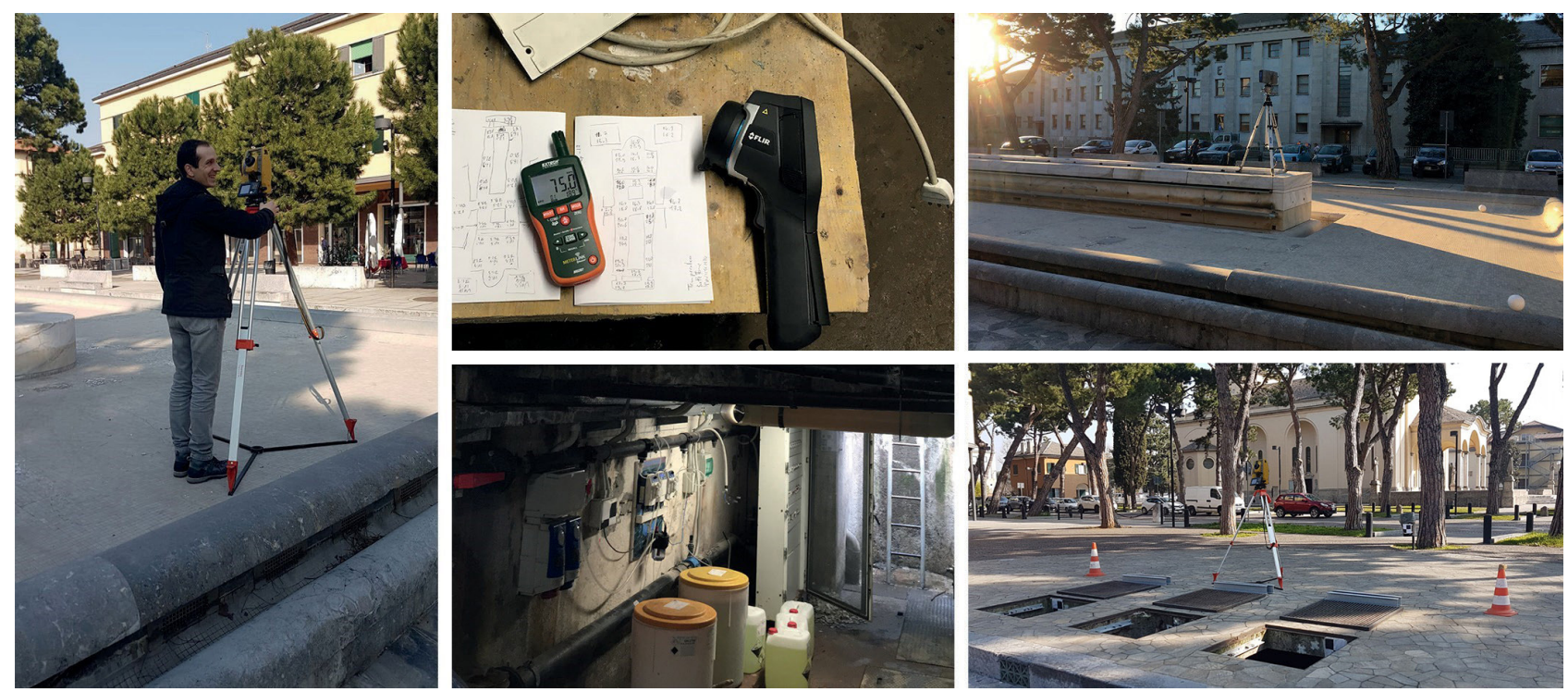

Figure 4. The phases of the survey: topographic network, 3D laser scanner acquisition, photo taking and thermographic-hygrometric analysis 
ventional photos) or photoelectric photos (digital photography). Laser scanner images, a third group, have arrived on the scene in recent years. These images include information on distance associated with each image element (Kraus 2007).

Karl Kraus, one of the fathers of modern geomatics, was among the first to have understood the potential of the integration of the different systems as belonging to a single multi-instrumental survey method. He predicted what is now possible with modern computer vision-based $3 \mathrm{D}$ reconstruction software, using data provided by both passive and active sensors: an automatic image and laser data processing method for orientation and alignment as well as 3D modelling and rendering. The process is performed automatically by the software without operator input using machine learning algorithms.

The restitution of a complete 3D model, with high resolution, high accuracy and good colour quality is not easy. It requires training, technical and practical skills, advanced software and high-performance hardware systems. Automation is a support to the surveyor, but it is necessary that the measurements and processing be carried out with expertise and under his direct control. A machine runs processes fast and with few mistakes, and, for this reason, it can be of great help to man. However, to this day, it does not yet have human intelligence, which alone can critically analyse the different situations and choose the right solution. The integrated survey is still a 'semi-automatic process' that cannot be separated from strict control of the operator. It will never become an autonomous, machine-managed process (as many people, even for commercial purposes, often suggest).

Measurement of the Dalmine fountain was carried out with these bases in mind. The most appropriate techniques were chosen relative to the conditions of the fountain and the need to examine the model. All of the data acquired from different instruments were processed in the same environment, 3DFlow ${ }^{\circledR}$ Zephyr software.
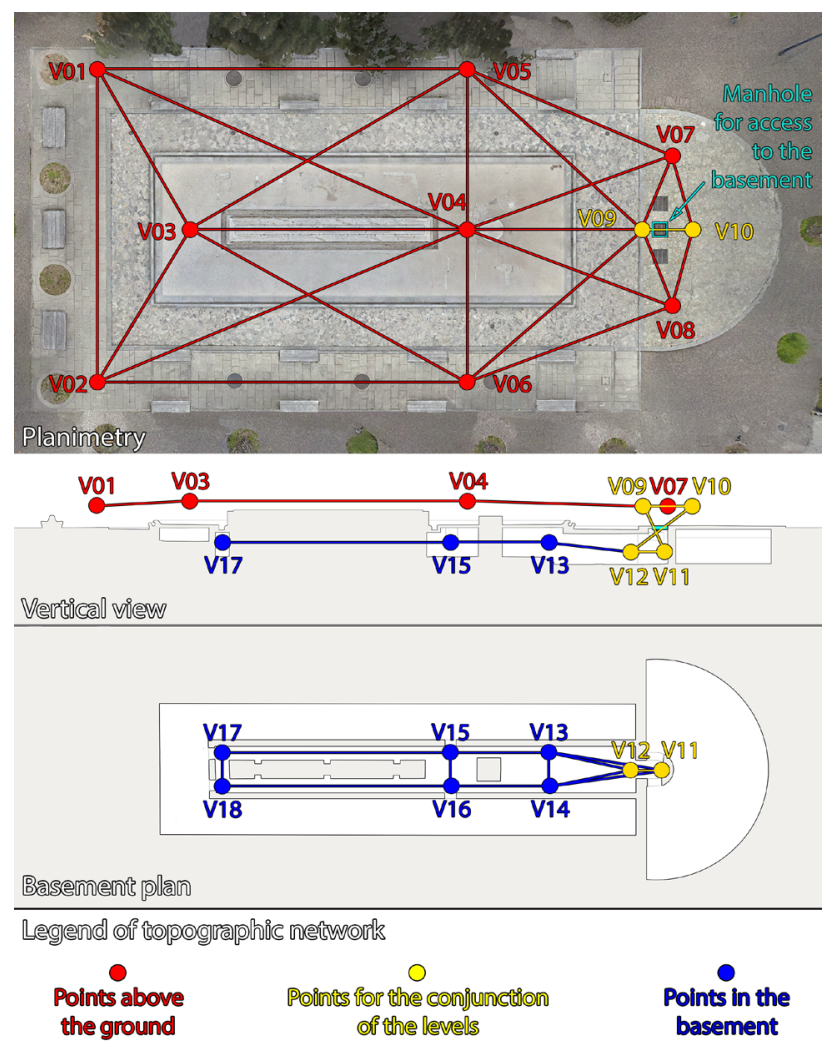

Figure 5. The topographic network and its vertices

\subsection{Measurement with topographic network}

The difficulty of defining a single reference system, common both to the aboveground parts of the square and to the underground spaces where the equipment is located, was solved by preparing a small topographical network. The vertices, 18 in all, were materialised with prisms placed on fixed tripods, whose coordinates were determined with a Topcon ${ }^{\circledR}$ OS- 105 total station (Fig. 5). The measurements were performed with a forced centring, a method that allows for the interchangeability between signal and instrument and results in an indeterminacy of less than a millimetre.

The resolution of the hyper-determined equations of the network (for the excess of both angular and distance measurements) was carried out through least-squares compensation software. In this specific case, the well-known commercial product MicroSurvey ${ }^{\circledR}$ Star*Net was used because it can combine ease of use and essential functions with great reliability and a high degree of rigour (Bonfanti, 2015). From the vertices of the network, through forward intersections and distance measurements, the coordinates of the paper target centres positioned on the ground and the fountain were acquired. They constitute, in large numbers and well-studied in geometry and spatial distribution, the ground control points (GCPs) of the 3D laser scanning and photogrammetric virtual data.

The millimetre measurement with total station was essential for checking the levels and slopes of the spillways and the four hydraulic devices that generate the fall of water from the first tank to the lower collection tank. Any difference in levelling (equal to or greater than the water head) is due to the functioning of the waterfalls, either increasing or decreasing the flow rate in some and cancelling it in others. The checks have shown that the movements of the structure have caused the lowering of its west side, therefore creating an irregular flow in the four spillways.

\subsection{The survey with active sensors}

The point cloud obtained from the survey with active sensors constituted the metric reference for the comparison and geo-referencing of the photogrammetric models (Shan et al., 2018). The acquisitions - 80 in total, consisting of 55 in the square and 25 in the basement - recorded only the reflectance values and not the colorimetric data.

They were conducted with an old device, the Faro ${ }$ Photon 120 , whose colour capture (carried out with an external camera) would have taken a very long time and been expensive. Ultimately, it would have been a useless procedure because the images would still have coloured only the discrete model to make it more readable. They would not have been useful for a continuous high-resolution model (Alshawabkeh, 2020).

The creation of a single project point cloud was carried out with an initial pre-alignment on target and, therefore, an approximation of the various portions using 'shape recognition' algorithms. The use of external references, such as spheres or chessboards, allowed a more rigid registration of the scans as well as a verification of inaccuracies based on the differences between the targets measured with the laser scanner and those measured with the topographic network (Liscio et al., 2016).

The registration phase was carried out through the proprietary software of the device, the Faro ${ }^{\circledR}$ Scene (Figs. 6 and 7), and the verification of the accuracy was carried out with the application of the ATS ${ }^{\circledR}$ Quality Manager, which is able to calculate the tensions and compensations and return GCP statistics. The excellent overlap of the individual clouds was thus ascertained with an average approximation contained within the instrumental precision $( \pm 1.5 \mathrm{~mm})$. 


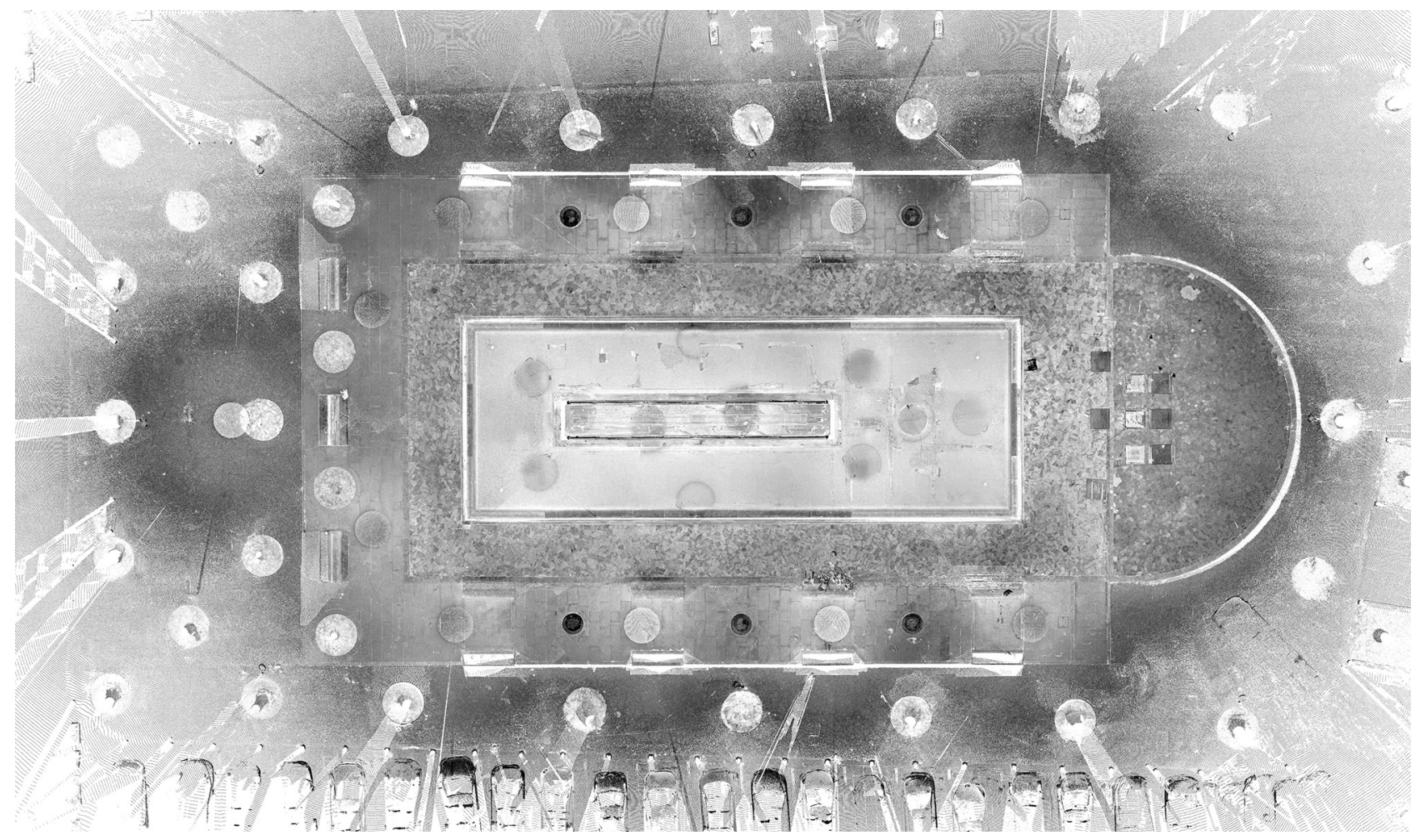

Figure 6. 3D laser scanning: orthographic projection of the point cloud

\subsection{The survey with passive sensors}

The generation of the photogrammetric 3D models was obtained by processing the photographic capture set. The images were taken with a Canon EOS 5D Mark II SLR camera with a Canon $24 \mathrm{~mm} / 1.4$ fixed lens at a resolution of 21 megapixels (5616 x $3744 \mathrm{px}$ ). A semi-automatic aperture-priority shooting mode was preferred, with low ISO film values and long shutter opening times. The files were saved in RAW format for the purpose of achieving the highest quality. The subsequent digital development in TIFF format made it possible to correct the errors that occurred during the capture (i.e. exposure, white balance and histogram).

This practice has also made it possible to obtain 'personal' and more realistic RGB images, thanks to the manipulation of the colour temperature, the adjustment of lights and shadows, the reduction of noise and the improvement of sharpness (Fig. 8). More than 750 shots were taken, with an overlap between frames of between $65 \%$ and $80 \%$ and a ground sample distance (GSD) value ranging from 1 to $4 \mathrm{~mm}$.

The processing of the collected data took place with the latest version of the 3 DFlow ${ }^{\circledR}$ Zephyr software. In fact, it is one of the commercial applications for photogrammetry capable of importing laser scan data and merging them within a single environment. The first phase of processing consists of the recognition by the software of significant points in the photographs followed by the subsequent matching of them between the homologous frames. Based on these indications, the $3 \mathrm{DF}{ }^{\circledR}$ Zephyr operated the spatial positioning of the cameras and the consequent generation of the scattered cloud. The workflow continued with the construction of the dense cloud, the conversion of the discontinuous point model into the continuous mesh and, finally, the reprojection on the faces of the individual triangles of the RGB images (after an accurate blending to ensure uniformity of exposure and colour). The georeferencing and scaling of the model was carried out based on the spatial coordinates of the GCPs, which also fulfilled the role of quality control points (QCPs). As in the procedures that involved the data acquired by passive sensors, some points were used to compare the differences between the coordinates of the models and those of the topographic network.

The final merging of the 3D laser scanner cloud and the photogrammetry mesh allowed for the generation of a final model characterised by both great metric accuracy and high colour quality (Fig. 9). This facilitated very detailed analyses and the overall reinterpretation of the building, both from geometric and material points of view.

\subsection{The analysis of deformations, thermo-hygrometric data and the state of alteration}

The processing of the final virtual model allowed, through the creation of Digital Elevation Model (DEM) images, the study of deformations (Sánchez-Aparicio et al., 2018) and the evaluation of the lowering of the main tank. The query of the point cloud model allowed for the definition of the actual dimensions of the building for the purpose of evaluating the thickness of the main slab and the vertical alignment of the structural elements. 3D laser scanning modelling allowed for the minimisation of any

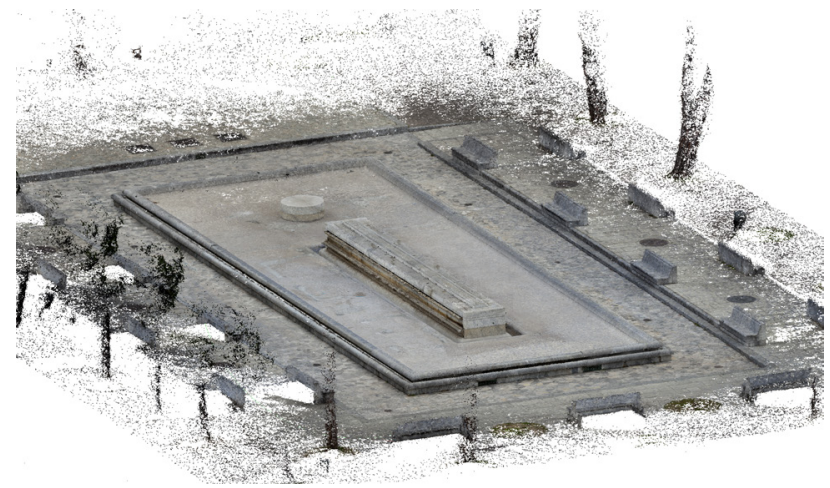

Figure 7. 3D laser scanning: the colored point cloud 

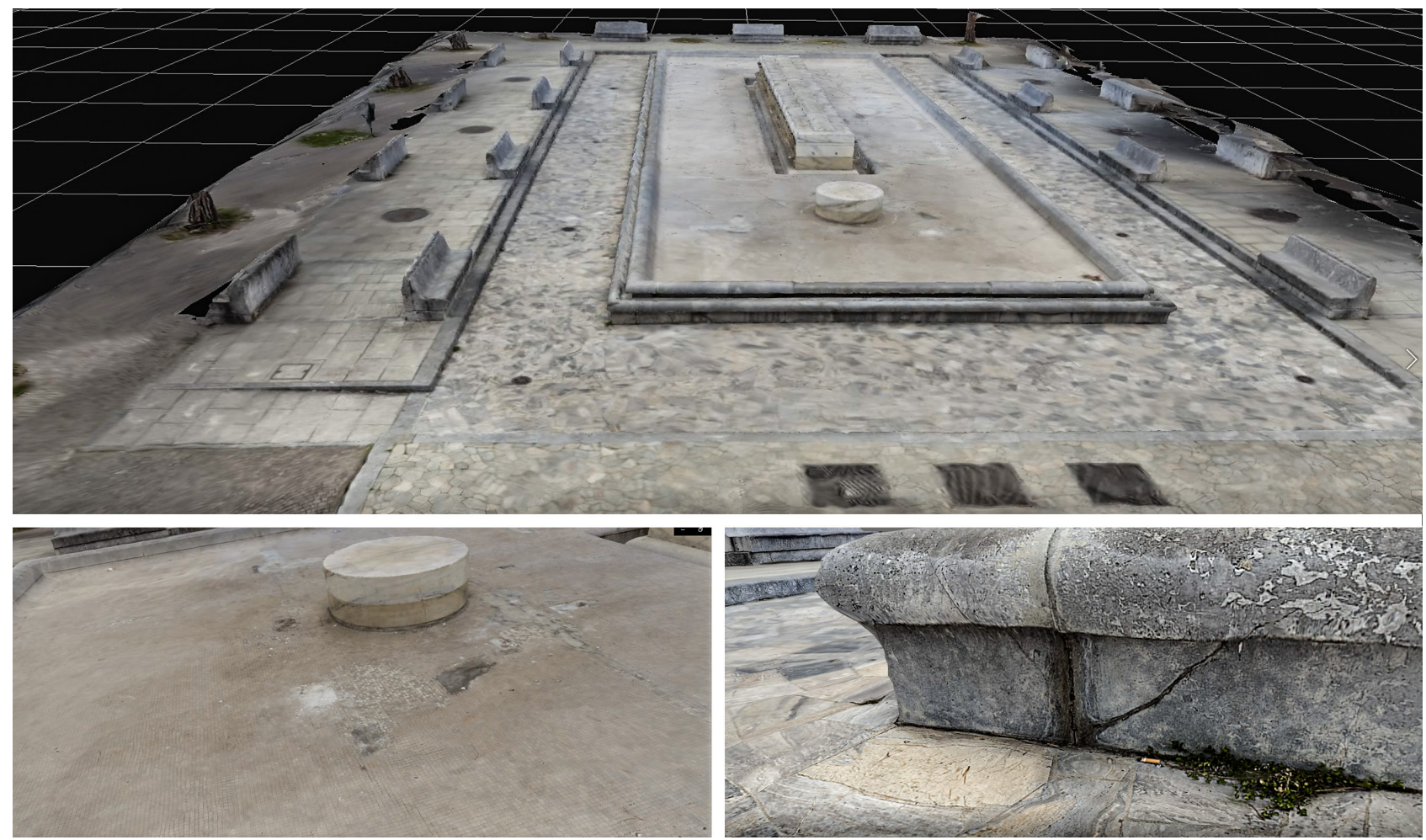

Figure 8. The Digital Photogrammetric survey: details of the textured mesh model

invasive probes, such as holes and openings. These interventions were necessary in the past, but they have resulted in serious effects on the maintenance of the hydraulic seals of the artifacts. False-colour mapping can highlight the construction differences, the deformations, and the previous maintenance interventions on the flooring as well as, most importantly, the detachments of the substrate of the mosaic tile flooring (Versaci et al., 2016).

The thermo-hygrometric analysis provided psychrometric and thermal information of the air and the most relevant surfaces of the basement. After identifying a set of 26 characteristic points well distributed along the accessible surface of the basement, the temperature values of the air and the floor as well as the intrados of the reservoir and relative humidity were measured locally. Measurements were made with a FLIR E60 thermal imaging camera and Extech MO297 thermo-hygrometer (Fig. 10).

The collected data were tabulated in CSV files and processed using the Golden Software ${ }^{\circledR}$ Surfer program to obtain a mapping of the entire surface. The analytical observation particularly highlighted critical thermo-hygrometric conditions on the west side, in the opposite direction of the ventilation openings located to the east, whereas, conversely, a high incidence of water percolation from the reservoir is concentrated.

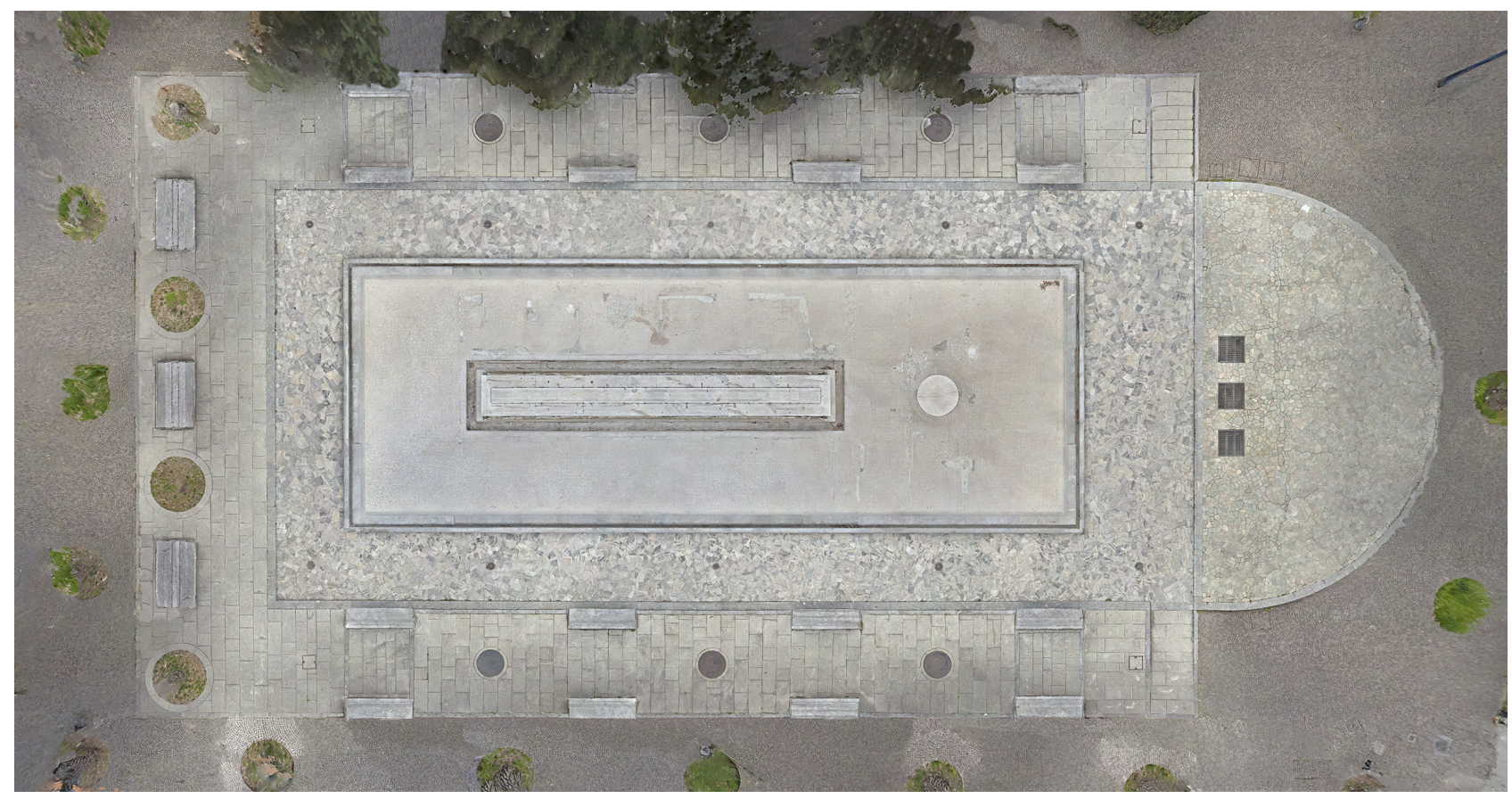

Figure 9. The orthographic projection from the integrated 3D Laser Scanner and Photogrammetric model 

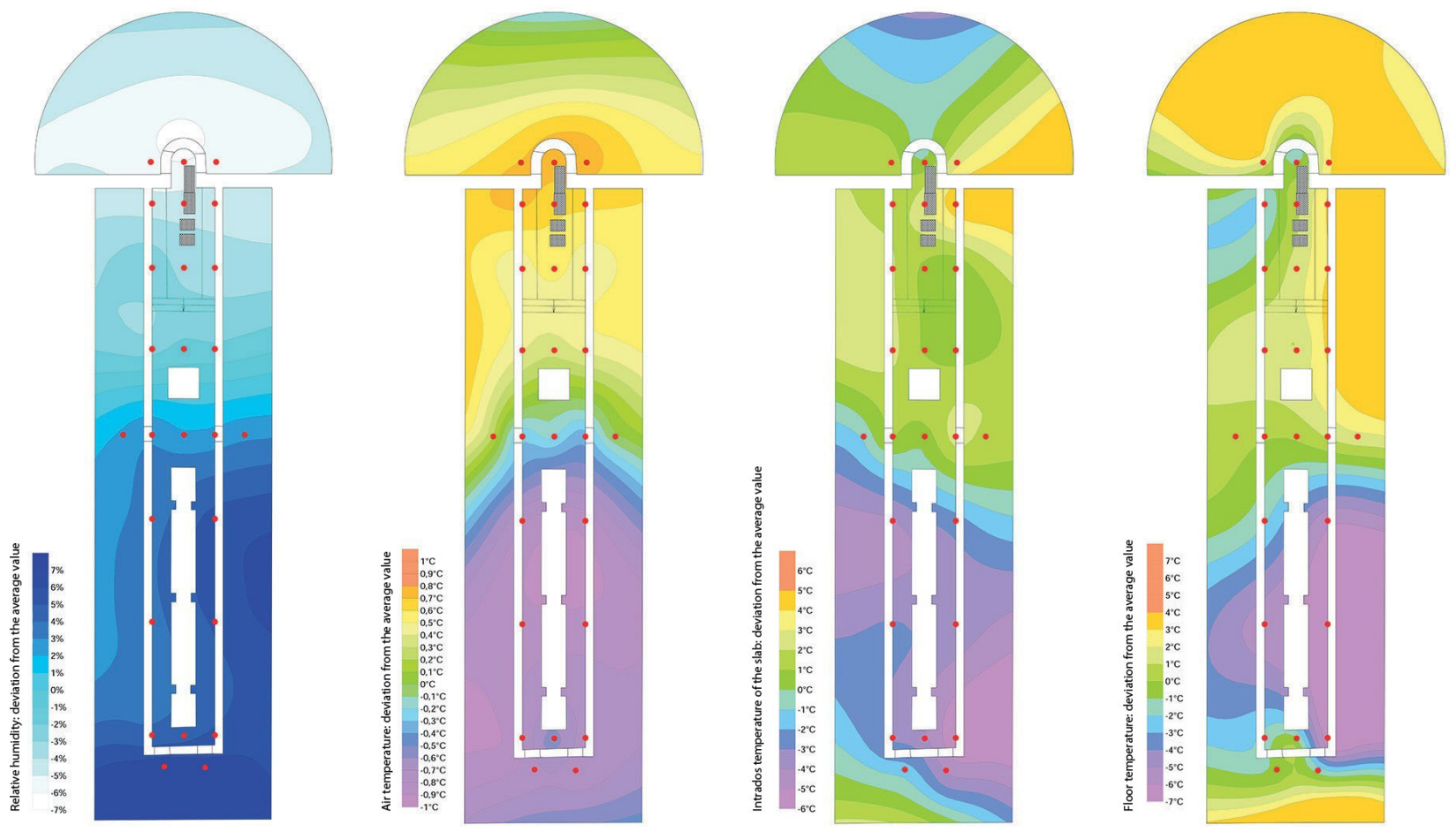

Figure 10. Thermo-hygrometric survey of the underground spaces: relative humidity, air temperature, intrados temperature, floor temperature

The undulation of the surface of the reservoir described by DEM (Fig. 11) must be considered together with the thermo-hygrometric analysis concerning the mapping of the degradation of the flooring. In fact, the presence of the typical forms of degradation that can involve the invasion of hydraulic artifacts, such as gaps, the result of previous swelling, fracturing and deficiencies, in addition to the appearance of vegetation and biological patinas on the surfaces, is widespread. The most damaged parts are concentrated in the basement, where the signs of water percolation in the concrete matrix are evident. The concretions (calcite and aragonite-based stalactites) present on the intrados of the slab allow for the evaluation of the temporal development of the crack pattern that favoured the carbonation of the concrete, the oxidation of the reinforcement bars and the expulsion of the concrete cover layer (Fig. 12). The analysis of the results provided a fairly defined picture of the health of the fountain and highlighted the current inadequacy of the hydraulic seal. A situation actually due to its original conception, to the definition of the construction details under construction and to the lack of care taken during the numerous maintenance and restoration interventions that took place over the years.

\section{CONCLUSIONS}

This geometrical and physical mapping of the Dalmine fountain can be adopted for the purpose of a conscious conservation project aimed firstly at repairing the damage that has occurred over the years. The small mosaic tiles that form the floor of the basin, ranging from soft grey to brown, produced a vibrating effect on the water surface. However, the waterproofing layer beneath the mosaic is bulging in many places and detaching from the bottom, which also results in the loss of large zones of tiles. Until recently, patches had apparently stopped but not resolved this problem because of the discontinuity of the waterproofing layer. As such, infiltration through the concrete slab continued. Moreover, the colour and even the size of the new tiles are slightly different from the old ones, which produces a bad appearance. Therefore, the desired substitution of the damaged

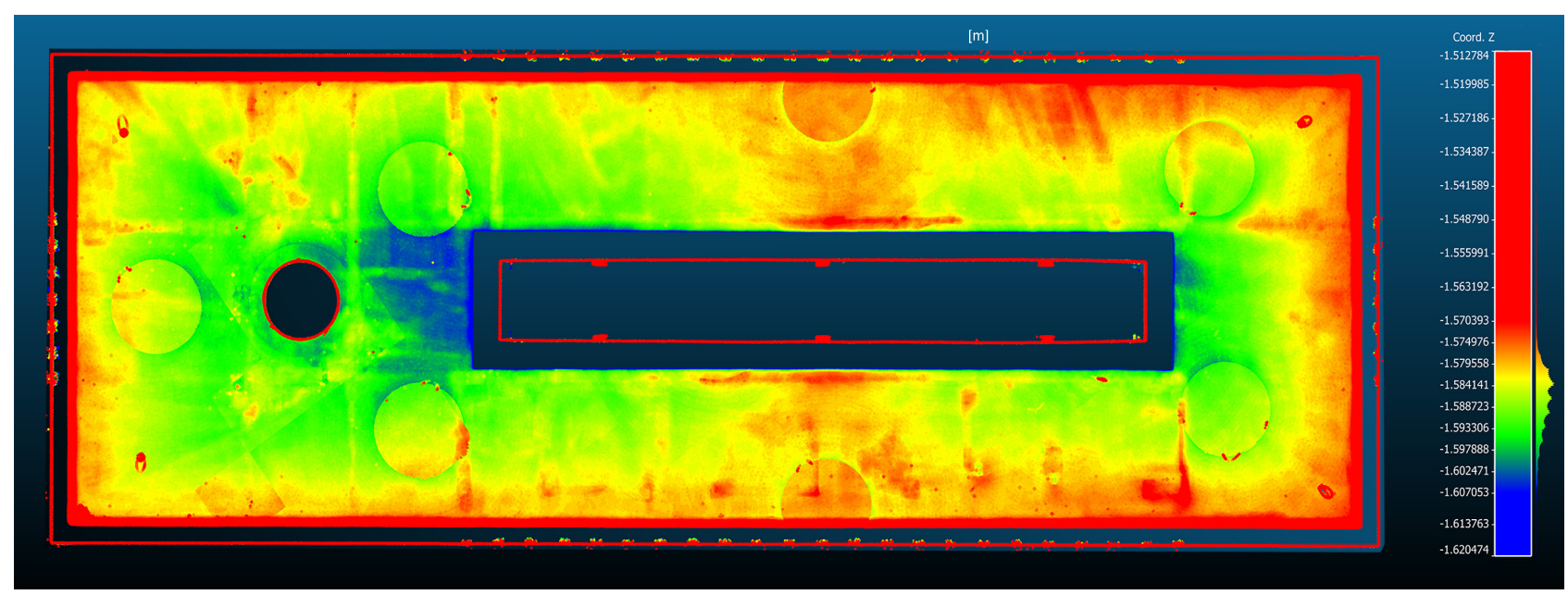

Figure 11. The DEM map that highlights the variation of the surface of the basin floor 

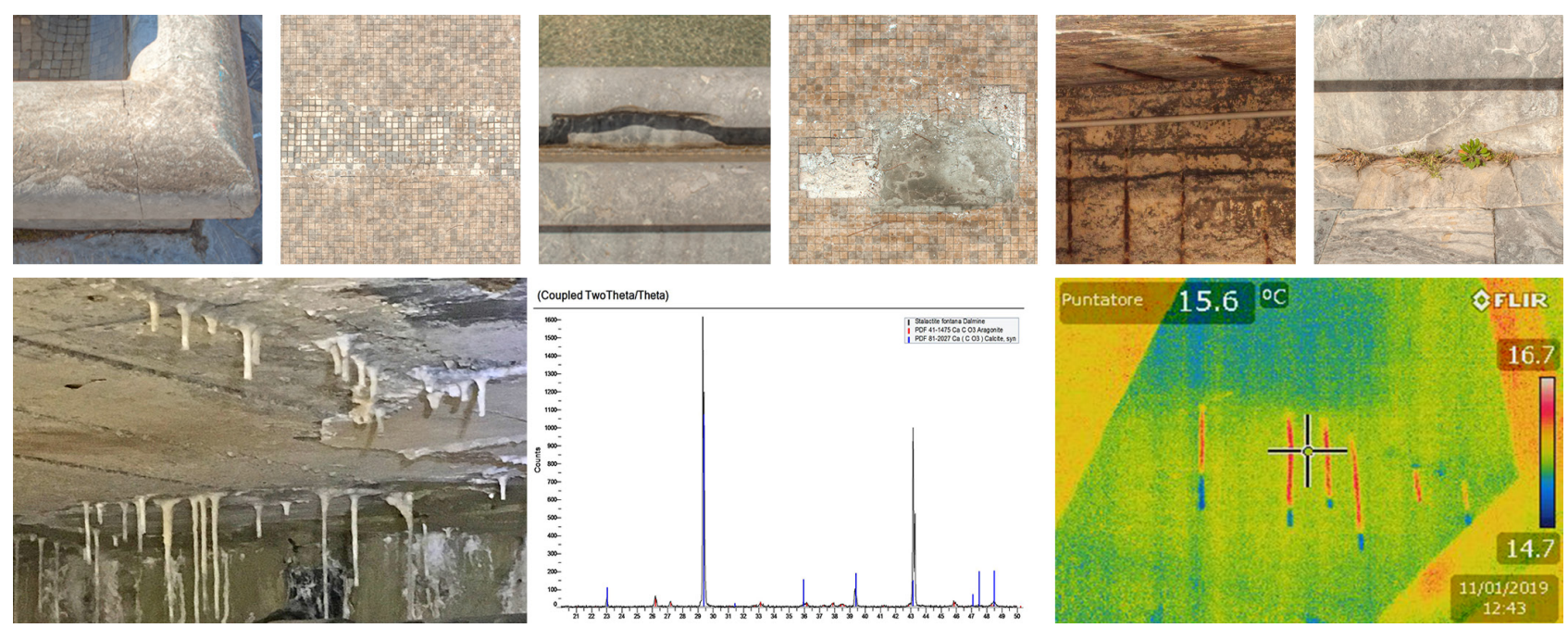

Figure 12. Some of the most relevant decay phenomena affecting the fountain: detachments, lacunae, cracks/fractures; besides, the persistent presence of water has caused the formation of concretions (stalactites). Diffraction analysis has highlighted the prevailing composition of aragonite and calcite

waterproof layer creates a delicate problem of maintenance or substitution of the mosaic, involving the question of whether to reproduce or preserve the original tile pattern.

On the other hand, the work planned for the basin could present an occasion to imagine a new solution for restoring the vision retrieving the image of the large stone wall that characterised this monumental fountain and restore this central space for the town of Dalmine.

\section{ACKNOWLEDGEMENTS}

The work has benefited from the 3D survey and diagnostics analisys conducted by the Lab_S.A.B.E. of the University of Bergamo, in collaboration with the Laboratory of Diagnostics and Restoration of Architectural and Cultural Heritage of the Kore University of Enna. The editorial responsibility of this essay is as follows: the paragraph 1 to $\mathrm{AV}$; paragraph 2, 3 and 3.4 to $\mathrm{AC}$; paragraph: $3.2,3.2$ and 3.3 to PA; paragraph 4 to all the authors. The authors would like to also thank the Prof. Giulio Mirabella Roberti for his advice and valuable support in this research.

\section{REFERENCES}

Alshawabkeh, Y., 2020. Color and laser data as a complementary approach for Heritage Documentation. Remote Sensing, (12), $1-25$.

Bonfanti C., 2015. Topographic and photogrammetric approaches for the multiscale documentation. Parthica: incontri di culture nel mondo antico, (17), 57-62.

Cardaci. A., Versaci, A., 2019. La trasformazione e il riuso del centro di Dalmine: dalla città di Greppi all'Urbe contemporanea. Atti dell'Ateneo di Scienze, Lettere ed Arti di Bergamo. Sestante Edizioni, Bergamo, 455-472.

Carpiceci, M., 2012. Fotografia digitale e architettura. Aracne, Roma.

Dequal, S., 1994. Fotogrammetria di Karl Kraus (con il contributo di Peter Waldhäusl, traduzione ed ampliamenti di Sergio Dequal). Libreria Universitaria Levrotto e Bella, Torino.

Kraus, K., 2007. Photogrammetry: geometry from Images and Laser Scans (2 edn). Walter de Gruyter, Berlin.
Gandin, M., 1941. Un villaggio modello. Documentari INCOM, Archivio storico Istituto Luce, https://patrimonio.archivioluce.com/ luce-web/detail/IL3000083691/1/un-villaggio-modello.html

Gandin, M., 1941. Andando verso il popolo. Documentari INCOM, Archivio storico Istituto Luce, https://patrimonio.archivioluce.com/luce-web/detail/IL3000052389/1/andando-verso-popolo.html Liscio E., Hayden A., Moody J., 2016. A comparison of the terrestrial laser scanner \& total station for scene documentation. Journal Association Crime Scene Reconstruction, (20), 1-8.

Lussana, C. Capelli, S., Brigo, J., 2019. Dalmine 1919-1939: industria, città, welfare. Propaganda11919-1939: un Ventennio a Bergamo e nel suo territorio. Sestante Edizioni, Bergamo, 77-92.

Lussana., C., 2003, Dalmine dall'impresa alla città: committenza industriale e architettura. Fondazione Dalmine, Bergamo.

Murtiyoso, A., Grussenmeyer, P., Suwardhi, D., Awalludin, R., 2018. Multi-Scale and Multi-Sensor 3D documentation of Heritage complexes in urban areas. ISPRS International Journal of Geo-Information, (7), 1-20.

Paris, L., 2011. Il rilievo del modello. Il disegno delle trasformazioni. Clean Edizioni, Napoli.1-10.

Ronchi. U., 1939. Dalmine ha risposto. La rivista di Bergamo, (3), 105-117.

Sánchez-Aparicio, L.J., Del Pozo, S., Ramos, L.F., Arce, A., Fernandes, F.M., 2018. Heritage Site preservation with combined radiometric and geometric analysis of TLS data. Automation in Construction, (85), 24-39.

Shan J., Toth C. K., 2018. Topographic laser ranging and scanning: principles and processing. Routledge, New York.

Versaci A., Cardaci A., Fauzia, L. R., 2016. Diagnostic activities for the planned and preventive conservation of mosaic pavements: the case study of the Triclinium of the Villa Romana del Casale (Sicily). Digital Heritage. Progress in Cultural Heritage: documentation, preservation, and protection. Springer, Cham, 241-253. 